\title{
Folium Sennae protects against hydroxyl radical-induced DNA damage via antioxidant mechanism: an in vitro study
}

\author{
Jian Lin ${ }^{1 \dagger}$, Xican Li ${ }^{i^{* \dagger}}$, Lu Han ${ }^{1}$, Fei Li ${ }^{2}$, Wenbiao Lu' ${ }^{1}$, Ye Bai ${ }^{2}$ and Dongfeng Chen ${ }^{2 *}$
}

\begin{abstract}
Background: In the study, Folium Sennae (FS) was firstly extracted by various solvents to obtain five FS extracts. Then, five FS extracts were evaluated for the protective effects against $\bullet \mathrm{OH}$-induced DNA damage, antioxidant abilities in vitro, and chemical contents using various methods. On this basis, the correlation graphs between the pharmacological effects and chemical contents were plotted to obtain the correlation coefficients ( $R$ values). Finally, in order to obtain biological evidence, ethyl acetate extract of FS (EAFS) was investigated for the protective effect against -OH-induced MSCs (mesenchymal stem cells) damage using MTT (3-(4,5-dimethylthiazol-2-yl)-2,5-diphenyl) assay.
\end{abstract}

Results: The pharmacological assays indicated that five FS extracts could effectively protect against $\cdot$ OH-induced DNA damage. The correlation analysis suggested that the average $R$ values of total phenolics, total anthraquinones, aloeemodin, rhein, and emodin were respectively $0.843,0.833,0.753,0.820$, and 0.784 , while those of total sugars and total saponins were respectively 0.103 and 0.0068 . The mechanistic analysis revealed that five FS extracts could also scavenge $\cdot \mathrm{OH}, \cdot \mathrm{O}_{2}^{-}, \mathrm{DPPH} \cdot \& \mathrm{ABTS}^{+}$radicals, and reduce $\mathrm{Cu}^{2+}$ to $\mathrm{Cu}^{+}$. MTT assay revealed that the viability of MSCs which were treated with $\cdot \mathrm{OH}$ radicals has been effectively protected by EAFS ( 3 and $30 \mu \mathrm{g} / \mathrm{mL}$ ).

Conclusion: On this basis, it can be concluded that: (i) Folium Sennae exhibits a protective effect against $\cdot \mathrm{OH}$-induced damages to DNA and MSCs; (ii ) The effects may be attributed to phytophenols (especially aloe-emodin, rhein, and emodin), not sugars or saponins; (iii) They exert the protective action via hydrogen atom transfer (HAT) and/or sequential electron proton transfer (SEPT) mechanisms which make phenolic -OH moiety be oxidized to stable semi-quinone form; (iv) The stability of semi-quinone form can ultimately be responsible for the protective or antioxidant effect of phytophenols.

Keywords: Folium Sennae; DNA oxidative damage; Antioxidant mechanism; Hydroxyl-induced; Anthraquinones; ROS scavenging

\section{Background}

It is well known that the DNA oxidative damage by reactive oxygen species (ROS, especially hydroxyl radical - $\mathrm{OH})$ can be repaired via enzymatic or non-enzymatic mechanisms, and that enzymatic repair has been widely explored. Non-enzymatic repair, however, remains relatively unknown until now. Zheng and colleagues pointed

\footnotetext{
*Correspondence: lixican@126.com; cdf27212@21cn.com

${ }^{\dagger}$ Equal contributors

'School of Chinese Herbal Medicine, Guangzhou University of Chinese Medicine, Waihuan East Road No.232, Guangzhou Higher Education Mega Center, 510006 Guangzhou, PR China

${ }^{2}$ School of Basic Medical Science, Guangzhou University of Chinese Medicine, Guangzhou 510006, PR China
}

out that non-enzymatic repair plays a critic role in basic pharmacology \& toxicology, because it is one billion times faster than the enzymatic repair of DNA oxidative damage. The fast non-enzymatic repair is usually exerted by natural phytophenols occurring in medicinal plants (especially Chinese herbal medicines) (Zheng et al. 2010). However, some new questions are also raised. For instance, (i) When a Chinese herbal medicine (medicinal plant) is used for fast repair of the DNA damage, is the repair action of phytophenols implicated with the other components? (ii) How and why do phytophenols exert the repair effect on DNA damage?

Since a Chinese herbal medicine Folium Sennae (FS) showed resistance to mutagenic effect caused by DNA

\section{穴}


oxidative damage (Silva et al. 2008; Demple and Halbrook 1983), we thus used FS as a reference plant to provide the answer to the questions.

\section{Methods}

\section{Plant material and animals}

Folium Sennae (the leaves of Cassia angustifolia Vahi, Additional file 1) was purchased from Caizhilin Pharmacy located in Guangzhou University of Chinese Medicine (Guangzhou, China, Lot No. YPA3A0001), and authenticated by Professor Shuhui Tan. A voucher specimen was deposited in our laboratory. Sprague-Dawley (SD) rats of 4 weeks of age were obtained from the animal centre of Guangzhou University of Chinese Medicine.

\section{Chemicals}

Trolox ( \pm - 6-hydroxyl-2,5,7,8-tetramethlyhromane-2-carboxylic acid), BHA (butylated hydroxyanisole), $\mathrm{DPPH} \bullet$ (1,1-diphenyl-2-picrylhydrazyl radical), pyrogallol, neocuproine (2,9-dimethyl-1,10-phenanthroline) and FolinCiocalteu reagent were purchased from Sigma Aldrich Trading Co. (Shanghai, China); ABTS [2,2'-azino-bis(3ethyl-benzothiazoline-6-sulfonic acid diammonium salt)] and D-2-deoxyribose were obtained from Amresco Co. (Solon, OH, USA); DNA sodium salt (fish sperm) was purchased from Aladdin Chemistry Co. (Shanghai, China); Aloe-emodin, rhein and emodin were purchased from National Institute for the Control of Pharmaceutical and
Biological Products (Beijing, China). Methanol and water were of HPLC grade. Dulbecco's modified Eagle's medium (DMEM), foetal bovine serum (FBS) and 3-(4,5-dimethylthiazol-2-yl)-2,5-diphenyl (MTT) were purchased from Gibco (Grand Island, NY, USA); CD44 was purchased from Wuhan Boster Co., Ltd. (Wuhan, China). All other chemicals used were of analytical grade.

\section{Preparation of five extracts from Folium Sennae}

The dried Folium Sennae was ground into coarse powder then extracted in sequence with petroleum ether (60-90), ethyl acetate, absolute ethanol, 95\% ethanol and water by Soxhlet extractor for 6 hours (Figure 1). The extracts were filtered using a Büchner funnel and Whatman No. 1 filter paper. Each filtrate was concentrated to dryness under reduced pressure at $60^{\circ} \mathrm{C}$ using a rotary evaporator. The dried extracts were stored at $4{ }^{\circ} \mathrm{C}$ for analysis.

\section{Protective effect against hydroxyl-induced DNA damage}

The experiment was conducted according to our method (Li et al. 2013). Briefly, sample was dissolved in methanol at $4 \mathrm{mg} / \mathrm{mL}$. Various amounts $(18-45 \mu \mathrm{L})$ of sample methanolic solutions were then separately taken into mini tubes. After evaporating the sample solutions in tubes to dryness, $300 \mu \mathrm{L}$ of phosphate buffer $(0.2 \mathrm{~mol} / \mathrm{L}, \mathrm{pH} 7.4)$ was added to the sample residue. Subsequently, $50 \mu \mathrm{L}$ DNA sodium $(10.0 \mathrm{mg} / \mathrm{mL}), 75 \mu \mathrm{L} \mathrm{H}_{2} \mathrm{O}_{2}(33.6 \mathrm{mmol} / \mathrm{L})$, $50 \mu \mathrm{LeCl}_{3}(3.125 \mathrm{mmol} / \mathrm{L})$ and $100 \mu \mathrm{L} \mathrm{Na}_{2}$ EDTA

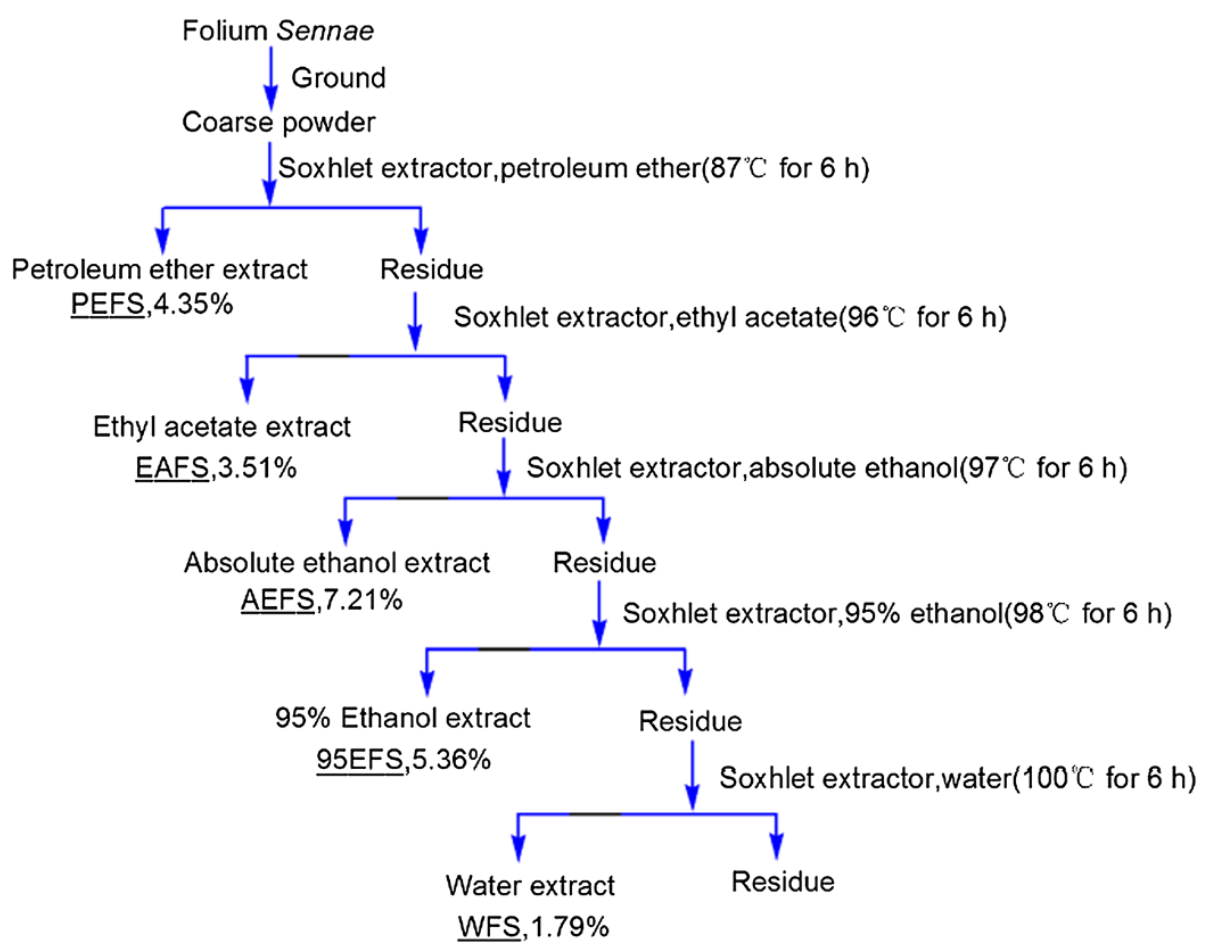

Figure 1 The preparation of five extracts from Folium Sennae. 
( $0.5 \mathrm{mmol} / \mathrm{L})$ were added. The reaction was initiated by adding $75 \mu \mathrm{L}$ of ascorbic acid $(12 \mathrm{mmol} / \mathrm{L})$. After incubation in a water bath at $50^{\circ} \mathrm{C}$ for $20 \mathrm{~min}$, the reaction was terminated by adding $250 \mu \mathrm{L}$ of trichloroacetic acid (10 g/ $100 \mathrm{~mL}$ water). The color was then developed by addition of $150 \mu \mathrm{L}$ of TBA (2-thiobarbituric acid) (5\%, in 1.25\% $\mathrm{NaOH}$ aqueous solution) and heated in an oven at $105^{\circ} \mathrm{C}$ for $15 \mathrm{~min}$. The mixture was cooled and absorbance was measured at $530 \mathrm{~nm}$ against the buffer (as blank). The percent of protection against DNA damage is expressed as follows:

$$
\text { Protective effect } \%=\frac{A_{0}-A}{A_{0}} \times 100 \%
$$

Where $A_{O}$ is the absorbance of the control without sample, and $A$ is the absorbance of the reaction mixture with sample.

\section{Hydroxyl $(\cdot \mathrm{OH})$ radical-scavenging assay}

The experiment of $\bullet \mathrm{OH}$ radical-scavenging was conducted in terms of our improved method (Li 2013). In brief, the sample methanol solution $(4 \mathrm{mg} / \mathrm{mL}, 9-36 \mu \mathrm{L})$ was separately added into tubes. After evaporating the sample solutions in the tubes to dryness, $400 \mu \mathrm{L}$ of phosphate buffer (0.2 $\mathrm{mol} / \mathrm{L}, \mathrm{pH} 7.4)$ was added to the sample residue. Subsequently, $50 \mu \mathrm{L}$ deoxyribose $(50 \mathrm{mmol} / \mathrm{L}), 50 \mu \mathrm{L} \mathrm{H}_{2} \mathrm{O}_{2}$ $(50 \mathrm{mmol} / \mathrm{L}), 50 \mu \mathrm{L} \mathrm{FeCl} 3(3.2 \mathrm{mmol} / \mathrm{L})$ and $50 \mu \mathrm{L}$ $\mathrm{Na}_{2}$ EDTA $(1 \mathrm{mmol} / \mathrm{L})$ were added. The reaction was initiated by mixing $50 \mu \mathrm{L}$ ascorbic acid $(1.2 \mathrm{mmol} / \mathrm{L})$ and the total volume of the reaction mixture was adjusted to $800 \mu \mathrm{L}$ with buffer. After incubation at $50^{\circ} \mathrm{C}$ for $20 \mathrm{~min}$, the reaction was terminated by $500 \mu \mathrm{L}$ trichloroacetic acid (5 g/100 mL).

The color was then developed by addition of $500 \mu \mathrm{L}$ TBA ( $1 \mathrm{~g} / 100 \mathrm{~mL}$, in $1.25 \% \mathrm{NaOH}$ aqueous solution) and heated in an oven at $105^{\circ} \mathrm{C}$ for $15 \mathrm{~min}$. The mixture was cooled and absorbance was measured at $530 \mathrm{~nm}$ against the buffer (as blank). The inhibition percentage for $\mathrm{OH}$ is expressed as follows:

$$
\text { Inhibition } \%=\frac{A_{0}-A}{A_{0}} \times 100 \%
$$

where, $A_{0}$ is the $A_{530 n m}$ of mixture without sample, and $A$ is the $A_{530 n m}$ of the mixture with sample.

\section{Superoxide anion $\left(\cdot \mathrm{O}_{2}^{-}\right)$radical-scavenging assay}

Measurement of superoxide anion $\left(\cdot \mathrm{O}_{2}{ }^{-}\right)$scavenging activity was based on our method (Li 2012). Briefly, the sample was dissolved in methanol at $4 \mathrm{mg} / \mathrm{mL}$. The sample solution $(x \mu \mathrm{L}$, where $x=0,50,100,150,200$ and $250 \mu \mathrm{L}$ ) was mixed with $2950-x \mu \mathrm{L}$ Tris- $\mathrm{HCl}$ buffer (0.05 mol/L, pH 7.4) containing $\mathrm{Na}_{2}$ EDTA (1 mmol/L). When $50 \mu \mathrm{L}$ pyrogallol $(60 \mathrm{mmol} / \mathrm{L}$ in $1 \mathrm{mmol} / \mathrm{L} \mathrm{HCl})$ was added, the mixture was shaken at room temperature immediately. The absorbance at $325 \mathrm{~nm}$ of the mixture was measured (Unico 2100, Shanghai, China) against the Tris- $\mathrm{HCl}$ buffer as blank every $30 \mathrm{~s}$ for $5 \mathrm{~min}$. The $\cdot \mathrm{O}_{2}{ }^{-}$ scavenging ability was calculated as:

$$
\text { Inhibition } \%=\frac{\left(\frac{A_{325 n \text { m,control }}}{T}\right)-\left(\frac{A_{325 n m, \text { sample }}}{T}\right)}{\left(\frac{A_{325 n m, \text { control }}}{T}\right)} \times 100 \%
$$

Here, $\Delta A_{325 \mathrm{~nm}}$, control is the increase in $\mathrm{A}_{325 \mathrm{~nm}}$ of the mixture without the sample and $\Delta A_{325 n m \text {, sample }}$ is that with the sample; $\mathrm{T}=5 \mathrm{~min}$. The experiment temperature was $37^{\circ} \mathrm{C}$.

\section{$\mathrm{DPPH} \bullet$ radical-scavenging assay}

$\mathrm{DPPH} \bullet$ radical-scavenging activity was determined as described (Li et al. 2012a). Briefly, $1 \mathrm{~mL} \mathrm{DPPH} \bullet$ ethanolic solution $(0.1 \mathrm{mmol} / \mathrm{L})$ was mixed with $0.5 \mathrm{~mL}$ sample alcoholic solution $(0.0267-0.1333 \mathrm{mg} / \mathrm{mL})$. The mixture was kept at room temperature for $30 \mathrm{~min}$, and then measured with a spectrophotometer (Unico 2100, Shanghai, China) at $519 \mathrm{~nm}$. The DPPH• inhibition percentage was calculated as:

$$
\text { Inhibition } \%=\frac{A_{0}-A}{A_{0}} \times 100 \%
$$

Where $A$ is the absorbance with samples, while $A_{O}$ is the absorbance without samples.

\section{$\mathrm{ABTS}^{+}$• radical-scavenging assay}

The $\mathrm{ABTS}^{+}$- -scavenging activity was measured as described (Li et al. 2009) with some modifications. The $\mathrm{ABTS}^{+} \cdot$ was produced by mixing $0.2 \mathrm{~mL}$ ABTS diammonium salt $(7.4 \mathrm{mmol} / \mathrm{L})$ with $0.2 \mathrm{~mL}$ potassium persulfate $(2.6 \mathrm{mmol} / \mathrm{L})$. The mixture was kept in the dark at room temperature for $12 \mathrm{~h}$ to allow completion of radical generation, then diluted with 95\% ethanol (about $1: 50)$ so that its absorbance at $734 \mathrm{~nm}$ was $0.70 \pm 0.02$. To determine the radical-scavenging activity, $1.2 \mathrm{~mL}$ aliquot of diluted $\mathrm{ABTS}^{+}$- reagent was mixed with $0.3 \mathrm{~mL}$ of sample ethanolic solution $(6.7-33.3 \mu \mathrm{g} / \mathrm{mL})$. After incubation for $6 \mathrm{~min}$, the absorbance at $734 \mathrm{~nm}$ was read on a spectrophotometer (Unico 2100, Shanghai, China). The percentage inhibition was calculated as:

$$
\text { Inhibition } \%=\frac{A_{0}-A}{A_{0}} \times 100 \%
$$

Here, $A_{O}$ is the absorbance of the mixture without sample, $A$ is the absorbance of the mixture with sample.

\section{$\mathrm{Cu}^{2+}$-reducing power assay}

The cupric ions $\left(\mathrm{Cu}^{2+}\right)$ reducing capacity was determined by the method (Li et al. 2012b), with minor modifications. 
Briefly, $125 \mu \mathrm{L} \mathrm{CuSO}_{4}$ aqueous solution (0.01 mol/L), $125 \mu \mathrm{L}$ neocuproine ethanolic solution $(7.5 \mathrm{mmol} / \mathrm{L})$ and (750-x) $\mu \mathrm{L} \quad \mathrm{CH}_{3} \mathrm{COONH}_{4}$ buffer solution $(0.1 \mathrm{~mol} / \mathrm{L}$, $\mathrm{pH} 7.5)$ were brought to test tubes with different volumes of samples $(1 \mathrm{mg} / \mathrm{mL}, x=25-125 \mu \mathrm{L})$. Then, the total volume was adjusted to $1000 \mu \mathrm{L}$ with the buffer and mixed vigorously. Absorbance against a buffer blank was measured at $450 \mathrm{~nm}$ after $30 \mathrm{~min}$ (Unico 2100, Shanghai, China). The relative reducing power of the sample as compared with the maximum absorbance, was calculated by the formula:

$$
\text { Relative reducing effect } \%=\frac{A-A_{\min }}{A_{\max }-A_{\min }} \times 100 \%
$$

where, $A_{\text {max }}$ is the maximum absorbance at $450 \mathrm{~nm}$ and $A_{\text {min }}$ is the minimum absorbance in the test. $A$ is the absorbance of sample.

\section{Determination of total phenolics}

The total phenolics contents of the five FS extracts were determined using a modified Folin-Ciocalteu colorimetric method ( $\mathrm{Li}$ et al. 2012b). In brief, $0.1 \mathrm{~mL}$ sample methanolic solution $(1 \mathrm{mg} / \mathrm{mL})$ was mixed with $0.5 \mathrm{~mL}$ Folin-Ciocalteu reagent $(0.25 \mathrm{~mol} / \mathrm{L})$. The mixture was left standing for $3 \mathrm{~min}$, followed by the addition of $\mathrm{Na}_{2} \mathrm{CO}_{3}$ aqueous solution $(1.0 \mathrm{~mL}, 15 \%$, w/v). After standing at room temperature for $30 \mathrm{~min}$, the mixture was centrifuged at $3500 \mathrm{r} / \mathrm{min}$ for $3 \mathrm{~min}$. The absorbance of the supernatant was measured at $760 \mathrm{~nm}$ (Unico 2100, Shanghai, China). The determinations were performed in triplicate, and the calculations were based on a calibration curve obtained with quercetin. The result was expressed as quercetin equivalents in milligrams per gram of extract.

\section{Determination of total sugars}

The content of total sugars was evaluated in terms of the phenol-sulfuric acid method (Li et al. 2012c). An aliquot of sample solution $(0.2 \mathrm{~mL}, 1 \mathrm{mg} / \mathrm{mL})$ was placed in a test tube, and the volume was adjusted to $2 \mathrm{~mL}$ with distilled water. Then $1 \mathrm{~mL}$ of $5 \%$ phenol solution and $5 \mathrm{~mL}$ of concentrated sulfuric acid were added. After incubation for $20 \mathrm{~min}$ at room temperature, the reaction mixture was measured using a spectrophotometer (Unico 2100) at $490 \mathrm{~nm}$. The standard curve was prepared using different concentrations of laminarin and the results were expressed as laminarin in milligrams per gram extract.

\section{Determination of total saponins}

The content of total saponins was measured according to the method (Li et al. 2012c). Sample methanolic solution $(0.15 \mathrm{~mL}, 2 \mathrm{mg} / \mathrm{mL})$ was taken in a test tube. After the methanol solvent was removed at $80^{\circ} \mathrm{C}, 0.1 \mathrm{~mL}$ vanillin-acetic acid solution $(5 \mathrm{mg} / \mathrm{mL})$ and $0.4 \mathrm{~mL}$ perchloric acid were added to the sample residue. The reaction mixture was incubated at $70^{\circ} \mathrm{C}$ for $15 \mathrm{~min}$, then cooled immediately and diluted by $1.25 \mathrm{~mL}$ acetic acid. After $10 \mathrm{~min}$, the absorbance of the diluted solution was measured at $540 \mathrm{~nm}$ (Unico 2100) against a blank control, which contained all reagents except for sample. Quantification was based on the standard curve for oleanolic acid $(9.14-54.86 \mu \mathrm{g} / \mathrm{mL})$. The results were expressed in milligrams of oleanolic acid equivalents per gram of extract.

\section{Determination of total anthraquinones}

The total anthraquinones content was determined by the colorimetric method (Zhang et al. 2005). In brief, the sample methanol solution $(0.4 \mathrm{~mL}, 4 \mathrm{mg} / \mathrm{mL})$ was separately added into tubes. After the methanol solvent was removed at $70^{\circ} \mathrm{C}$, the sample residue was dissolved with $2 \mathrm{~mL}$ distilled water, followed by the addition of $1 \mathrm{~mL}$ concentrated hydrochloric acid. The reaction mixture was incubated at boiling water for $30 \mathrm{~min}$ and shaken continually, then cooled and extracted by diethyl ether (10 mL/time, 3-5 times). After the extract was combined and evaporated to dryness, $6 \mathrm{~mL} \mathrm{NaOH}$ aqueous solution $(5 \%, \mathrm{w} / \mathrm{v})$ was added and mixed vigorously. After standing at room temperature for $45 \mathrm{~min}$, the reaction mixture was measured using a spectrophotometer (Unico 2100) at $520 \mathrm{~nm}$. The standard curve was prepared using different concentrations of emodin and the results were expressed as emodin in milligrams per gram extract.

\section{HPLC analysis for aloe-emodin, rhein and emodin}

Aloe-emodin, rhein and emodin in FS extracts were identified by the retention times and the peak areas were used to characterize the relative contents in the study. HPLC analysis was performed on a Syltech P510 system (Los Angeles, California, USA), equipped with a Diamonsil C18 $(250 \mathrm{~mm} \times 4.6 \mathrm{~mm}, 5 \mu \mathrm{m})$ column (Dikma Co., Beijing, China). All samples were dissolved in methanol at $10 \mathrm{mg} / \mathrm{mL}$ and filtered using $0.45 \mu \mathrm{m}$ filters. The mobile phase consisted of methanol- $0.1 \%$ phosphoric acid (85:15, v: v) and the flow rate was $0.5 \mathrm{~mL} /$ min, injection volume was $15 \mu \mathrm{L}$, detection wavelength was $254 \mathrm{~nm}$.

\section{Protective effect against $\cdot \mathrm{OH}$-induced damage to MSCs (MTT assay)}

MSCs culture was carried out according to our previous report (Chen et al 2007) with slight modifications. In brief, bone marrow was obtained from the femur and tibia of rat. The marrow samples were diluted with DMEM (LG: low glucose) containing 10\% FBS. MSCs were prepared by gradient centrifugation at $900 \mathrm{~g}$ for 
Table 1 The $\mathbf{R}$ (correlation coefficient) values between chemical contents and antioxidant levels (1/IC 50 value)

\begin{tabular}{|c|c|c|c|c|c|c|c|}
\hline & Total phenolics & Total sugars & Total saponins & Total anthraquinones & Aloe-emodin & Rhein & Emodin \\
\hline Protection against DNA damage & 0.769 & 0.330 & -0.589 & 0.747 & 0.773 & 0.753 & 0.662 \\
\hline$\cdot \mathrm{OH}$ scavenging & 0.814 & 0.561 & -0.571 & 0.650 & 0.326 & 0.650 & 0.575 \\
\hline$\cdot \mathrm{O}_{2}^{-}$scavenging & 0.865 & 0.182 & 0.328 & 0.743 & 0.674 & 0.719 & 0.664 \\
\hline DPPH• scavenging & 0.91 & -0.112 & 0.155 & 0.997 & 0.922 & 0.994 & 0.983 \\
\hline $\mathrm{ABTS}^{+} \cdot$ scavenging & 0.918 & -0.036 & 0.158 & 0.962 & 0.872 & 0.958 & 0.931 \\
\hline $\mathrm{Cu}^{2+}$-reducing & 0.784 & -0.306 & 0.56 & 0.896 & 0.952 & 0.884 & 0.886 \\
\hline Average & 0.843 & 0.103 & 0.0068 & 0.833 & 0.753 & 0.820 & 0.784 \\
\hline
\end{tabular}

$30 \mathrm{~min}$ on $1.073 \mathrm{~g} / \mathrm{mL}$ Percoll. The prepared cells were detached by treatment with $0.25 \%$ trypsin and passaged into cultural flasks at $1 \times 10^{4} / \mathrm{cm}^{2}$. MSCs at passage 3 were evaluated for cultured cell homogeneity using detection of CD44 by flow cytometry and were used for the investigation.

These MSCs were seeded at $1 \times 10^{4}$ cells per well in 96-well plates. After adherence for $24 \mathrm{hr}$, these MSCs were then divided into normal, model, and EAFS (sample) groups. Compared with the normal group, MSCs in the model and sample groups were treated with the mixture of $\mathrm{FeCl}_{2}(100 \mu \mathrm{M})$ followed by $\mathrm{H}_{2} \mathrm{O}_{2}(50 \mu \mathrm{M})$ for 25 minutes, and then which be removed, MSCs of the normal and model groups were both cultured in serum-free DMEM (low glucose) but the sample groups were incubated with EAFS (at 3 and $30 \mu \mathrm{g} / \mathrm{mL}$ ) which were diluted by serum-free DMEM (low glucose) for $24 \mathrm{hr}$. All groups had five independent wells. After incubation, $20 \mu \mathrm{L}$ MTT $(5 \mathrm{mg} / \mathrm{mL}$ ) was added and then incubated for further $3 \mathrm{~h}$. Culture medium was discarded and was replaced with $150 \mu \mathrm{L}$ DMSO. Absorbance at $490 \mathrm{~nm}$ was measured by a Bio-Kinetics reader (PE-1420; Bio-Kinetics Corporation, Sioux Center, IA, USA). In the experiment, culture with serum medium was used for the control group and each sample test was repeated in five independent wells.

\section{Statistical analysis}

All determinations were conducted in triplicate and all the results were calculated as Mean $\pm \mathrm{SD}(\mathrm{SD})$. The $\mathrm{IC}_{50}$ values were calculated by linear regression analysis. All linear regression in this paper was analyzed by Origin 6.0 professional software (OriginLab Corporation, Northampton, MA, USA). Statistical comparisons between means were performed using one-way analysis of variance (ANOVA). Values of $\mathrm{p}<0.05$ were considered statistically significant. The analysis was performed using SPSS software 13.0 (SPSS Inc., Chicago, IL) for windows.

\section{Results and discussion}

In the study, FS was firstly extracted by various solvents to prepare five FS extracts, i.e., petroleum ether extract (PEFS), ethyl acetate extract (EAFS), absolute ethanol extract (AEFS), 95\% ethanol extract (95EFS), and water extract (WFS) (Figure 1). Five FS extracts were then determined using an in vitro model developed by our laboratory ( $\mathrm{Li}$ et al. 2013). The results indicated that FS

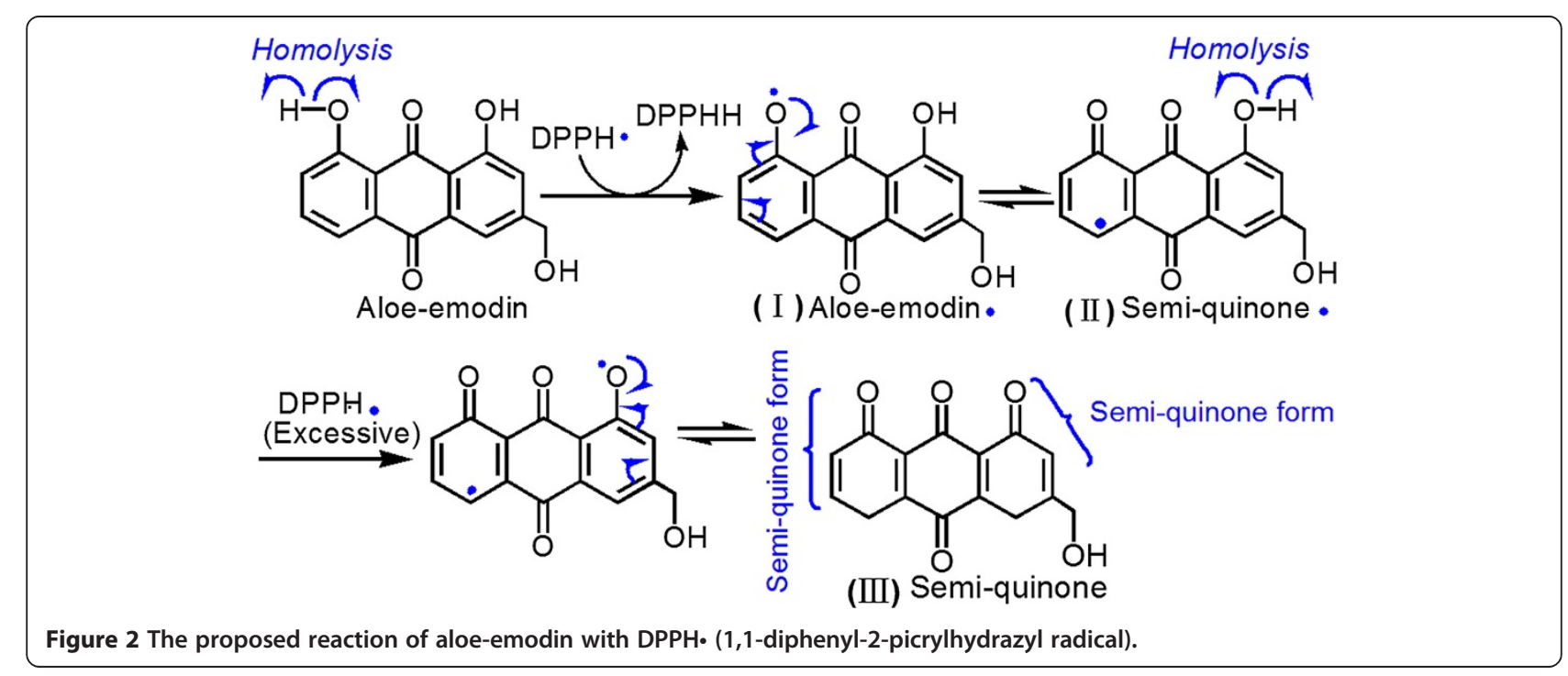




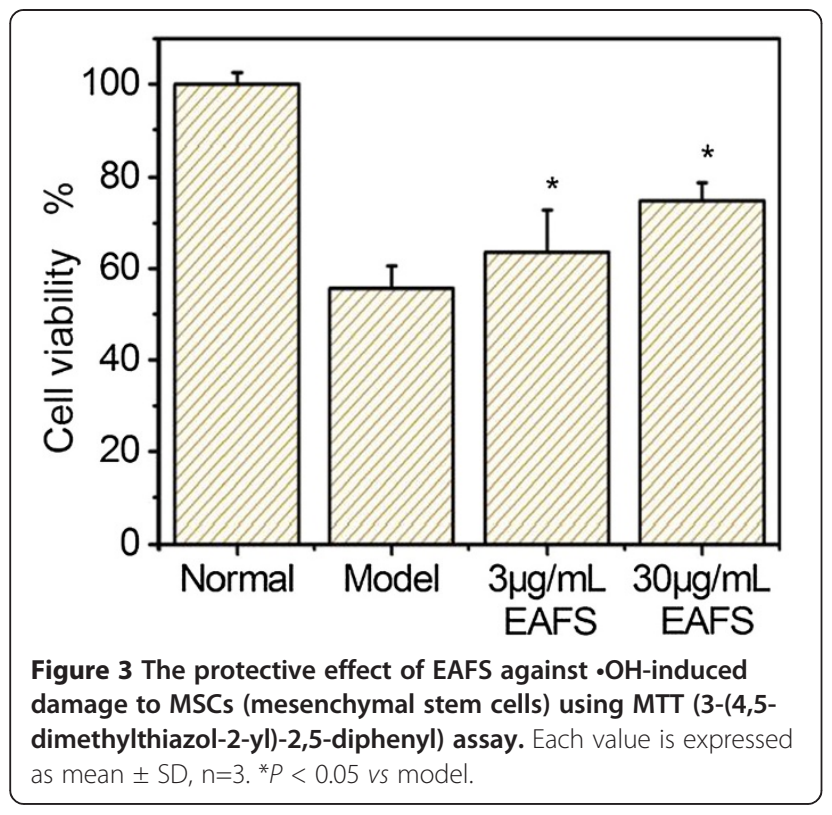

extracts could effectively protect against $\cdot \mathrm{OH}$-induced DNA damage (Additional file 2).

In order to identify which chemical component can be responsible for the protective effect, we further measured the chemical contents in the FS extracts, including total phenolics, total sugars, total saponins, total anthraquinones, aloe-emodin, rhein, and emodin (Additional file 2). On this basis, the correlation graphs (Additional file 3) between chemical contents and the protective effect $\left(1 / \mathrm{IC}_{50}\right.$ values, Additional file 2$)$ were plotted to obtain the correlation coefficients ( $\mathrm{R}$ values). As seen in Table 1 , the $R$ values of total phenolics, total sugars and total saponins were respectively $0.769,0.330$, and -0.589 . It means that the protective effect of FS may arise from phytophenols, not sugars or saponins. This assumption was further confirmed by the average $R$ values. The average $R$ value of total phenolics was 0.843 , while those of total sugars and total saponins were much lower $(0.103$ and 0.0068 respectively). As we know, phytophenols in FS mainly include phenolic anthraquinones, therefore, total anthraquinones also exhibited a higher $\mathrm{R}$ value $(0.833$, Table 1). Among phenolic anthraquinones, however, aloeemodin, rhein, and emodin are well-known in FS. In our study, aloe-emodin, rhein, and emodin also possessed higher $\mathrm{R}$ values $(0.753,0.820$, and 0.784 respectively). Now it is clear that the protective effect against $\bullet \mathrm{OH}$-induced DNA damage of FS can be mainly attributed to phytophenols, especially three phenolic anthraquinones aloeemodin, rhein, and emodin, not sugars or saponins.

Furthermore, non-enzymatic repair by phytophenols has been reported to be via ROS scavenging and direct DNA radical repairing approaches (Zheng et al. 2010). In order to explore the ROS scavenging possibility of FS, we used our methods ( $\mathrm{Li}$ 2013; Li 2012) to investigate its ROS scavenging abilities, including $\cdot \mathrm{OH}$-scavenging and $\cdot \mathrm{O}_{2}{ }^{-}$-scavenging. Our results showed that five FS extracts could eliminate both $\bullet \mathrm{OH}$ and $\cdot \mathrm{O}_{2}^{-}$radicals (Additional file 2). It suggests that ROS scavenging may play a role in fast non-enzymatic repair of FS.

To study the ROS scavenging mechanism of FS, we determined its radical-scavenging abilities on DPPH• and $\mathrm{ABTS}^{+} \bullet$. The data in Additional file 2 indicated that FS could effectively inhibit $\mathrm{DPPH} \bullet$ and $\mathrm{ABTS}^{+} \bullet$ radicals. $\mathrm{DPPH} \bullet$ scavenging has been demonstrated to be a hydrogen atom $(\mathrm{H} \bullet$ ) transfer process (HAT) (Bondet et al. 1997). For example, the proposed reaction for aloeemodin to scavenge $\mathrm{DPPH} \cdot$ can be briefly illustrated in Figure 2. In the process, phenolic $-\mathrm{OH}$ underwent homolysis to give $\mathrm{H} \bullet$ and aloe-emodin $\bullet$ radical (I). $\mathrm{H} \bullet$ was then transferred to $\mathrm{DPPH} \cdot$ to generate $\mathrm{DPPH}-\mathrm{H}$ molecule. Meanwhile, (I) might transform into semi-quinone radical (II), which could be further extracted $\mathrm{H} \bullet$ by excess $\mathrm{DPPH} \bullet$ to form the stable semi-quinone (III).

Unlike $\mathrm{DPPH} \bullet$ radical, $\mathrm{ABTS}^{+} \bullet$ radical cation, however, needs only an electron $(\boldsymbol{e})$ to neutralize the positive charge and $\mathrm{ABTS}^{+} \cdot$ scavenging is regarded as an electron $(\boldsymbol{e})$ transfer process (Aliaga and Lissi 1998). Therefore, in the reaction of aloe-emodin with $\mathrm{ABTS}^{+} \cdot$ radical, aloe-emodin was thought to produce an electron $(\boldsymbol{e})$ and $\mathrm{H}^{+}$ion. The electron $(\boldsymbol{e})$ was then donated to $\mathrm{ABTS}^{+} \cdot$ to form stable ABTS molecule. Meanwhile, aloe-emodin changed to the aloe-emodin • radical (I), which could also be converted into semi-quinone radical (II) and semi-quinone (III) in excess $\mathrm{ABTS}^{+} \bullet$ (Additional file 4). The electron $(\boldsymbol{e})$ transfer mechanism was also supported by the $\mathrm{Cu}^{2+}$-reducing power assay. As we know, reductive reaction is actually an electron $(\boldsymbol{e})$ - donating process. Five FS extracts, however, could successfully reduced $\mathrm{Cu}^{2+}$ to $\mathrm{Cu}^{+}$(Additional file 2). Since $\boldsymbol{e}$ transfer is always accompanied by deprotonation, so it is called sequential electron proton transfer (SEPT) (Iuga et al. 2011).

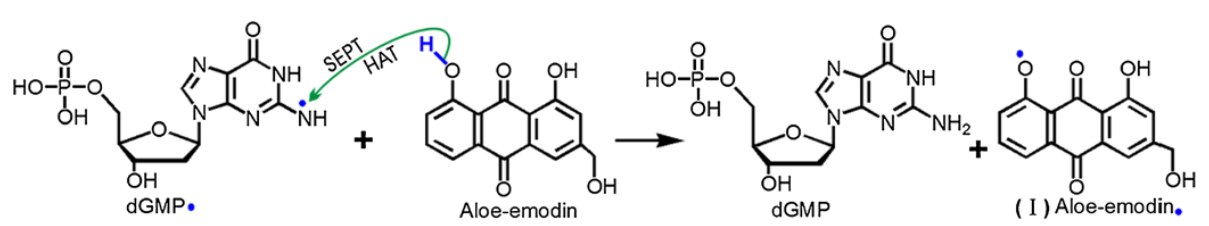

Figure 4 The proposed reaction for aloe-emodin to repair dGMP• (2'-deoxyguanosine-5'-monophosphate radical). 
To obtain biological evidence, the effect of EAFS which has been regarded as the most effective extract among five FS extracts in the antioxidant assays above, was further estimated using the MTT assay. The results suggested that the viability of MSCs has been effectively protected by EAFS (at 3 and $30 \mu \mathrm{M}$, Figure 3) when they were treated with $\bullet \mathrm{OH}$ radicals. Based on previous reports (Urbanek et al. 2005; Estrada et al. 2013), we assumed that the protective effect against $\cdot \mathrm{OH}$ radical-induced damage to MSCs might be directly associated with its repair of oxidative DNA damage.

Taken together, the fact that FS could effectively scavenge both $\mathrm{DPPH} \bullet$ and $\mathrm{ABTS}^{+} \cdot$ radicals, and reduce $\mathrm{Cu}^{2+}$, implies that phytophenols in FS exert ROS scavenging action via HAT and/or SEPT mechanisms. Both HAT and SEPT mechanisms, however, can similarly make phytophenols be oxidized to semi-quinone (III). As the final oxidized product, semi-quinone (III) is actually a stable form bearing a large $\pi-\pi$ conjugation (Figure 2 ). Hence, the protective or antioxidant effect of FS may be attributed to the phenolic $-\mathrm{OH}$ moiety, and ultimately to the stability of semi-quinone form.

Of course, the HAT and SEPT mechanisms can be used for the interpretation of ROS scavenging. For example, in water at physiological pH 7.4, aloe-emodin could scavenge $\cdot \mathrm{OH}$ radical via SEPT mechanism. As we know, carbonyl groups $(\mathrm{C}=\mathrm{O})$ can greatly withdraw electron through $\pi-\pi$ conjugative systems to enhance the acidity of phenolic -OH groups in aloe-emodin. In the case, the acidity might therefore predominate over its chemical action in the weak alkaline environment, and phenolic $-\mathrm{OH}$ would firstly ionize to yield $\mathrm{H}^{+}$ion, and aloe-emodin ${ }^{-}$which subsequently donated an electron (e) to form aloe-emodin' (I) (Additional file 5). However, in the lipidic environment, aloe-emodin scavenged $\cdot \mathrm{OH}$ radical via a $\mathrm{HAT}$ mechanism: in the case, phenolic $-\mathrm{OH}$ in aloe-emodin homolyzed to produce aloe-emodin $\bullet$ radical $(\mathrm{I})$, and a hydrogen atom $(\mathrm{H} \bullet$ ) which further combined $\cdot \mathrm{OH}$ radical to yield $\mathrm{H}_{2} \mathrm{O}$ molecule (Additional file 6). Actually, both possible mechanisms are supported by the previous report (Iuga et al. 2012).

More importantly, both SEPT and HAT mechanisms can also be used for the interpretation of direct repairing on DNA radicals, e.g., 2'-deoxyguanosine-5'-monophosphate radical (dGMP•). The dGMP• may be generated via the reaction of nucleotide and $\bullet \mathrm{OH}$ radical (Additional file 7). Aloe-emodin, however, could repair dGMP• radical via SEPT and/or HAT mechanisms (Figure 4). As seen in Figure 3, aloe-emodin was oxidized by dGMP• radical to aloe-emodin• radical (I).

\section{Conclusion}

In conclusion, Folium Sennae exhibits a protective effect against $\bullet \mathrm{OH}$-induced damages to DNA and MSCs. The effects may be attributed to phytophenols (especially aloe-emodin, rhein, and emodin), not sugars or saponins. They exert the protective action via hydrogen atom transfer (HAT) and/or sequential electron proton transfer (SEPT) mechanisms which make phenolic - $\mathrm{OH}$ moiety be oxidized to stable semi-quinone form. The stability of semi-quinone form can ultimately be responsible for the protective or antioxidant effect of phytophenols.

\section{Additional files}

\section{Additional file 1: The photos of Folium Sennae. \\ Additional file 2: The dose response curves and $\mathrm{IC}_{50}$ values of five FS extracts in all assays. \\ Additional file 3: Correlation graphs. \\ Additional file 4: The proposed reaction of aloe-emodin with ABTS $^{+}$. \\ Additional file 5: The proposed reaction for aloe-emodin to scavenge -OH via SEPT.}

Additional file 6: The proposed reaction for aloe-emodin to scavenge -OH via HAT.

Additional file 7: The proposed reaction of $\cdot \mathrm{OH}$ radical attack dGMP to form dGMP.

\section{Abbreviations}

ROS: Reactive oxygen species; HAT: Hydrogen atom transfer; SEPT: Sequential electron proton transfer; FS: Folium Sennae; DPPH: 1,1-diphenyl-2picrylhydrazyl radical; dGMP•: 2'-deoxyguanosine-5'-monophosphate radical; ABTS: 2, 2'-azinobis (3-ethylbenzothiazoline-6-sulfonic acid); TBA: 2-thiobarbituric acid; PEFS: Petroleum ether extract; EAFS: Ethyl acetate extract; AEFS: Absolute ethanol extract; 95EFS: 95\% ethanol extract; WFS: Water extract.

\section{Competing interests}

The authors declare that they have no competing interests.

\section{Authors' contributions}

$X C L$ and $C D F$ designed the project and wrote the manuscript, $J L, F L$, and $Y B$ performed the analyses, $\mathrm{LH}$ and $\mathrm{WBL}$ revised the manuscript. All authors read and approved the final manuscript.

Received: 12 September 2013 Accepted: 7 January 2014 Published: 2 February 2014

\section{References}

Aliaga C, Lissi EA (1998) Reaction of 2, 2'-azinobis (3-ethylbenzothiazoline-6sulfonic acid (ABTS) derived radicals with hydroperoxides: Kinetics and mechanism. Int J Chem Kine 30:565-570

Bondet V, Brand-Williams W, Berset C (1997) Kinetics and mechanisms of antioxidant activity using the DPPH• free radical method. LWT-Food Sci Technol 30:609-615

Chen DF, Zeng HP, Du SH, Li H, Zhou JH, Li YW, Wang TT, Hua XC (2007) Extracts from plastrum testudinis promote proliferation of rat bone-marrow-derived mesenchymal stem cells. Cell Prolif 40:196-212

Demple B, Halbrook J (1983) Inducible repair of oxidative DNA damage in Escherichia coli. Nature 304:466-468

Estrada JC, Torres Y, Benguría A, Dopazo A, Roche E, Carrera-Quintanar L, Pérez RA, Enríquez JA, Torres R, Ramírez JC, Samper E, Bernad A (2013) Human mesenchymal stem cell-replicative senescence and oxidative stress are closely linked to aneuploidy. Cell Death Dis 4:e691

luga C, Alvarez-Idaboy JR, Vivier-Bunge A (2011) ROS initiated oxidation of dopamine under oxidative stress conditions in aqueous and lipidic environments. J Phys Chem B 115:12234-12246

luga C, Alvarez-ldaboy JR, Russo N (2012) Antioxidant activity of trans-resveratrol toward hydroxyl and hydroperoxyl radicals: a quantumchemical and computational kinetics study. J Org Chem 77:3868-3877 
Li X (2012) Improved pyrogallol autoxidation method: a reliable and cheap superoxide-scavenging assay suitable for all antioxidants. J Agric Food Chem 60:6418-6424

Li X (2013) Solvent effects and improvements in the deoxyribose degradation assay for hydroxyl radical-scavenging. Food Chem 141:2083-2088

Li X, Wu X, Huang L (2009) Correlation between antioxidant activities and phenolic contents of Radix Angelicae Sinensis (Danggui). Molecules 14:5349-5361

Li X, Chen D, Mai Y, Wen B, Wang X (2012a) Concordance between antioxidant activities in vitro and chemical components of Radix Astragali (Huangqi). Nat Prod Res 26:1050-1053

Li X, Lin J, Han W, Mai W, Wang L, Li Q (2012b) Antioxidant ability and mechanism of Rhizoma Atractylodes macrocephala. Molecules 17:13457-13472

Li X, Lin J, Gao YX, Han WJ, Chen DF (2012c) Antioxidant activity and mechanism of Rhizoma Cimicifugae. Chem Cent J 6:140

Li X, Mai W, Wang L, Han W (2013) A hydroxyl-scavenging assay based on DNA damage in vitro. Anal Biochem 438:29-31

Silva CR, Monteiro MR, Rocha HM, Ribeiro AF, Caldeira-de-Araujo A, Leitão AC (2008) Assessment of antimutagenic and genotoxic potential of senna (Cassia angustifolia Vahl.) aqueous extract using in vitro assays. Toxicol in Vitro 22:212-218

Urbanek K, Torella D, Sheikh F, Angelis AD, Nurzynska D, Silvestri F, Beltrami CA, Bussani R, Beltrami AP, Quaini F, Bolli R, Leri A, Kajstura J, Anversa P (2005) Myocardial regeneration by activation of multipotent cardiac stem cells in ischemic heart failure. Proc Natl Acad Sci USA 102:8692-8697

Zhang ZL, Shi YB, Zhou Y (2005) The comparison of the total anthraquinones content in different parts of Rubia cordifolia L. before and after charcoal. Lishizhen Med Mater Med Res 16:700-701

Zheng RL, Shi YM, Jia ZJ, Zhao CY, Zhang Q, Tan XR (2010) Fast repair of DNA radicals. Chem Soc Rev 39:2827-2834

doi:10.1186/1999-3110-55-16

Cite this article as: Lin et al:: Folium Sennae protects against hydroxyl radical-induced DNA damage via antioxidant mechanism: an in vitro study. Botanical Studies 2014 55:16.

\section{Submit your manuscript to a SpringerOpen ${ }^{\circ}$ journal and benefit from:}

- Convenient online submission

- Rigorous peer review

- Immediate publication on acceptance

- Open access: articles freely available online

- High visibility within the field

- Retaining the copyright to your article

Submit your next manuscript at $\gg$ springeropen.com 